\title{
Artificial Bee Colony Optimization of NOx Emission and Reheat Steam Temperature in a $1000 \mathrm{MW}$ Boiler
}

\author{
Xian-hua Gao $(\mathbb{D})$ and Zhi-gang Su $(\mathbb{D}$ \\ School of Energy and Environment, Southeast University, Nanjing, Jiangsu 210096, China \\ Correspondence should be addressed to Zhi-gang Su; zhigangsu@seu.edu.cn
}

Received 3 July 2019; Revised 10 September 2019; Accepted 30 September 2019; Published 11 November 2019

Academic Editor: Kauko Leiviskä

Copyright (C) 2019 Xian-hua Gao and Zhi-gang Su. This is an open access article distributed under the Creative Commons Attribution License, which permits unrestricted use, distribution, and reproduction in any medium, provided the original work is properly cited.

This paper puts forward a new viewpoint on optimization of boiler combustion, namely, reducing NOx emission while maintaining higher reheat steam temperature rather than reducing NOx emission while improving boiler efficiency like traditional practices. Firstly, a set of multioutputs nonlinear partial least squares (MO-NPLS) models are established as predictors to predict these two indicators. To guarantee better predictive performance, repeated double cross-validation (rdCV) strategy is proposed to identify the structure as well as parameters of the predictors. Afterward, some controllable process variables, taken as inputs of the predictors, are then optimized by minimizing NOx emission and maximizing reheat steam temperature via multiobjective artificial bee colony (MO-ABC). Results show that our rdCV-MO-NPLS model with MO-ABC optimization methods can reduce NOx emission synchronously and improve reheat steam temperature effectively compared with nondominated sorting genetic algorithm II (NSGA-II) and combustion adjustment experimental data on a real $1000 \mathrm{MW}$ boiler.

\section{Introduction}

Boiler combustion optimization of reducing nitrogen oxide (NOx, for short) has become a hot topic during the past three decades. There exist several currently typical ways in coping with the boiler combustion optimization problem. The first popular method is numerical simulation that is based on computational fluid dynamics (CFD) [1-3]. However, the optimal set points explored by numerical simulation cannot guarantee optimal value in practice due to inconsistencies between designed conditions in CFD and practical conditions. To consider this, it is interesting to take into account the abundant information originating from practical running data. Under such circumstance, the datadriven method is motivated.

The development of data-driven methods can be divided into two stages. At the first stage, researchers only focus on NOx emission reduction by using evolutional algorithms (EAs) to search the optimal set point of controllable process variables. The typical EAs include genetic algorithm (GA), particle swarm optimization (PSO), and ant colony optimization (ACO). Among them, GA is frequently used on boiler combustion optimization. For example, in $[4,5]$, artificial neural network (ANN) combined with GA is proposed to reduce NOx emission. And in [6], support vector machine (SVM) and conventional GA (CGA) are used on NOx emission reduction. Researchers can notice that only NOx emission is considered as the optimization objective in the above researches, but ignoring that the combustion system is a hybrid system which is coupled with other subsystems. The reduction of NOx usually plays great influence on other important parameters such as reheat steam temperature $\left(\mathrm{Tr},{ }^{\circ} \mathrm{C}\right)$. That is, the optimization of boiler combustion system is essentially a multiobjective optimization problem.

This issue with multiobjective optimization in boiler combustion systems has gained great attention at the second stage. Traditionally, boiler combustion optimization is implemented to reduce NOx emission and increase boiler efficiency by EAs (for example, see works [7-10]). ANNs with multiobjective GA (MOGA) are employed on boiler combustion optimization. Although the above methods have made significant contributions on reducing NOx emission while improving boiler efficiency, there still exist some unconsidered issues. Firstly, reheat steam temperature is always lower than its set value due to the requirement of 
meeting electric peak regulation. This phenomenon not only imposes a bad influence on the whole plant efficiency but also poses a threat to safe control of the boiler combustion system. Secondly, the precise calculation of boiler efficiency is hard to complete actually due to some practical issues. The third problem is the lack of effective modelling data, as historical running data are heavily coupled and incomplete. Therefore, it is urgent to improve reheat steam temperature.

Up to date, to the best of our knowledge, there is few literature on boiler combustion optimization to reduce NOx emission and improve reheat steam temperature simultaneously. Motivated by the above statements, this paper aims to reduce NOx emission while achieving higher reheat steam temperature by proposing a jointed optimization method. More precisely, a Multiple Output version of Nonlinear Partial Least Squares (MO-NPLS) regression model is first proposed to predict behaviors of NOx emission and reheat steam temperature synchronously. To achieve better performance, the structure and parameters of MO-NPLS are identified by repeated double cross validation ( $\mathrm{rdCV}$ ) rather than traditional $\mathrm{k}$-fold cross-validation strategy. Then, a multiobjective artificial bee colony (MO-ABC) algorithm is adopted to search optimal inputs of predictors that can achieve lower NOx emission and higher reheat steam temperature from Pareto front. The modelling data are from a combustion adjustment experiment conducted on a real $1000 \mathrm{MW}$ coal-fired boiler. It will be seen that our proposed method outperforms combustion adjustment experimental data and commonly used nondominated sorting genetic algorithm II (NSGA-II). Therefore, the main contributions of this paper can be summarized in three-fold:

(1) Both NOx emission and reheat steam temperature are firstly proposed in boiler combustion optimization. This strategy can reduce NOx emission while maintaining higher reheat steam temperature to guarantee the safety in boiler combustion system control as well as the improvement of whole plant efficiency.

(2) A MO-NPLS method with rdCV strategy is raised to establish the predictive model of both NOx emission and reheat steam temperature. This algorithm is powerful due to its strong generalization ability especially with small number of samples.

(3) A MO-ABC-based multiobjective optimization method is proposed on boiler combustion optimization. On the basis of the rdCV-MO-NPLS modelling method, our proposed MO-ABC algorithm can reduce NOx emission synchronously and improve reheat steam temperature effectively compared with NSGA-II and the experimental data.

The rest of the paper is organized as follows. In Section 2, the 1000 MW boiler combustion system and data sources are described. Section 3 establishes predictors used to predict behaviors of NOx emission and reheat steam temperature by rdCV-MO-NPLS. Then, Section 4 presents the joint optimization method by MO-ABC and the comparison with NSGAII and experimental data. Section 5 concludes this paper.

\section{Description of Combustion System}

In this section, the boiler combustion system is introduced, together with the dynamic characteristics of combustion system. And then, the data source used for modelling establishment and validation is presented.

2.1. Boiler Combustion System. Figure 1 illustrates a $1000 \mathrm{MW}$ tower-type ultrasupercritical boiler adopting the reheat system and air-staged combustion technique. As can be seen from Figure 1, a selective catalytic reduction (SCR) system is installed at the exit of convection flue gas and two air preheaters are arranged beneath the SCR system. Along vertical direction, the entire furnace is divided into three zones including main combustion zone, reduction zone, and burning-out zone. Furthermore, in the main combustion zone, twelve-level pulverized coal burners are equipped and correspond to six mills indexed by letters from $\mathrm{A}$ to $\mathrm{F}$ that are with burners $\mathrm{A} 1$ and $\mathrm{A} 2$ at the bottom to $\mathrm{F} 1$ and $\mathrm{F} 2$ at the top, respectively.

Generally, different coal allocations decided by the coal feeding rate of each mill will lead to different temperature fields and flame centers in the furnace. For instance, if more coal is supplied by bottom mills, the flame center will move downward. As a result, NOx production will reduce due to the extension of reductive zone; however, the reheat steam temperature ( $\mathrm{Tr}$ ) will decrease too because of less quality of heat. In the present work, although the coal feeding rate is a directly manipulated parameter, thermal load $\left(Q_{i}\right)$ is monitored instead by considering the diversity of coal types as follows:

$$
Q_{i}=\frac{B_{i}}{B_{0}} \cdot Q_{0}, \quad i \in\{A, B, \ldots, F\},
$$

where $B_{0}$ is the total coal fed by mills and $Q_{0}$ indicates the total thermal load.

In contrast to coal allocations, primary air is usually not adjusted because its main task is to transport pulverized power from mills, i.e., to match the pulverized coal. Secondary air, including that in the main combustion zone and separated overfire air (SOFA) in the burning-out zone, can be adjusted to improve combustion conditions in the boiler. To enhance reducibility in the main combustion zone so as to reduce NOx production, one can decrease secondary air in the main combustion zone with increase of SOFA ratio $\left(\alpha_{\text {SOFA }}\right)$ as the total air volume remains constant. Evidently, this parameter represents the ratio of secondary air to total air. More interestingly, higher reheat steam temperature can be achieved with higher $\alpha_{\text {SOFA }}$, but excessive $\alpha_{\text {SOFA }}$ will affect the combustion performance in the main combustion zone. However, the volume of secondary air in the main combustion zone is rather difficult to monitor due to tens of dampers in power plant. Instead, $\alpha_{\mathrm{SOFA}}$ is used and defined as

$$
\alpha_{\text {SOFA }}=\frac{\text { SOFA }}{\text { total air }}
$$

where total air $=$ primary air + secondary air. Considering that there is about $20 \%$ running oxygen $\left(\mathrm{O}_{2}\right)$ in total air. 


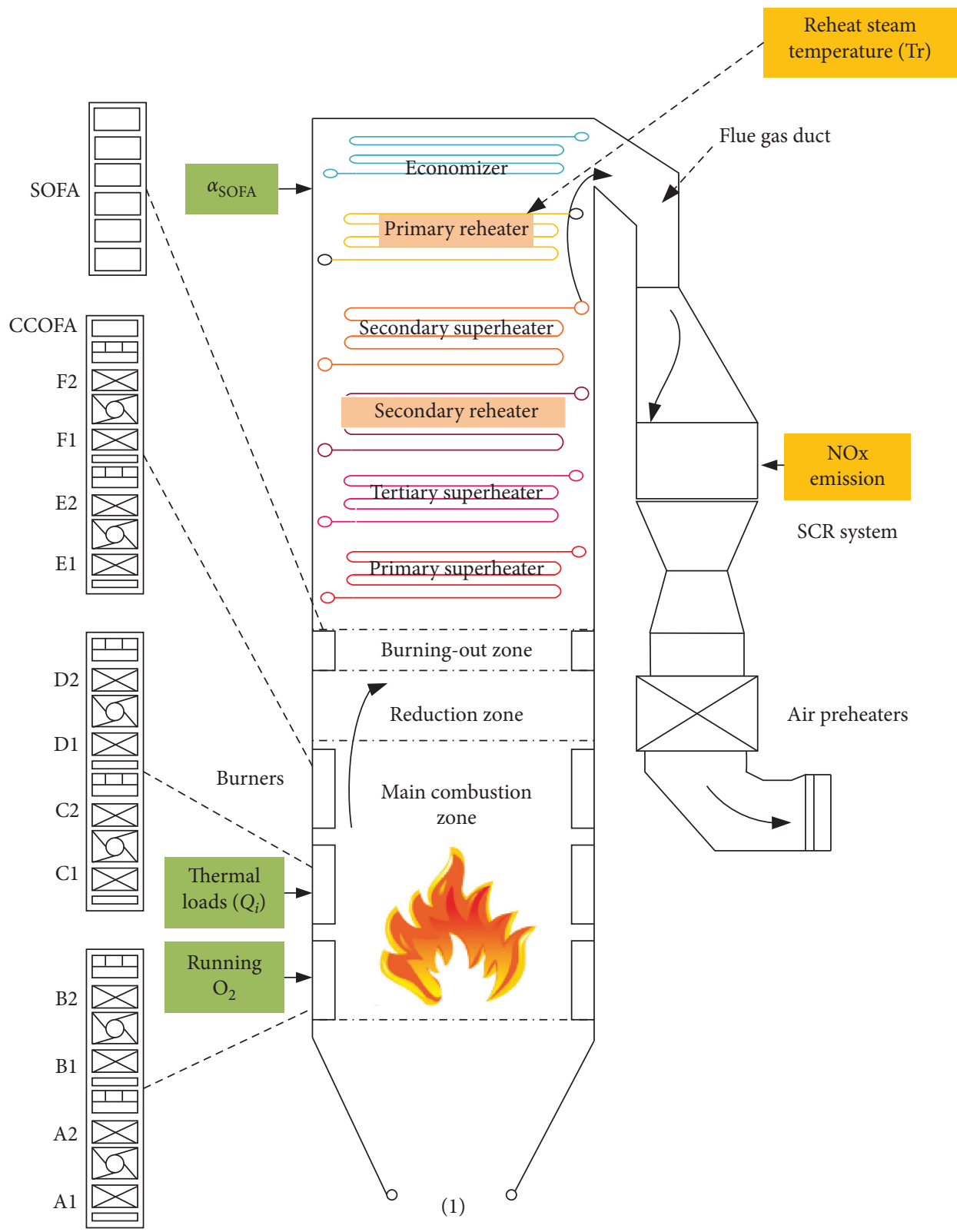

(2)

FIGURE 1: Schematic diagram of a $1000 \mathrm{MW}$ boiler combustion system: (1) boiler; (2) burners.

Therefore, the higher the running $\mathrm{O}_{2}$ is, the greater the total air volume will be.

In addition, notice that the higher the running $\mathrm{O}_{2}$ value is, the better combustion effect will be. Then, both NOx emission and reheat steam temperature will increase subsequently and vice versa. This means there exists an optimal $\alpha$ value, namely, optimal running $\mathrm{O}_{2}$.

In summary, to reduce NOx emission and increase reheat steam temperature synchronously heavily relies on the distribution of thermal loads $\left(Q_{i}\right)$, running $\mathrm{O}_{2}$, and $\alpha_{\text {SOFA }}$ in the furnace.

Remark 1. The burners at vertical direction are tilted within a range of $\pm 30^{\circ}$ to tune the reheat steam temperature $\left(\mathrm{Tr},{ }^{\circ} \mathrm{C}\right)$
[11]. At low load condition, even if burners have been already fully titled up, the reheat steam temperature will be still significantly lower than its desirable setpoint. This will impose a bad influence on whole power plant efficiency (the whole plant efficiency $\eta_{c p}=\eta_{b} \cdot \eta_{p} \cdot \eta_{i} \cdot \eta_{m} \cdot \eta_{g}$ where $\eta_{i}$ is plant thermal efficiency which depends on reheat steam temperature).

2.2. Data Source. The value of reheat steam temperature from actual operational conditions is not accurate as it is controlled by a closed-loop temperature system. Therefore, we adopted the data collected from a combustion adjustment experiment shown in Supplementary file of the 1000 MW power plant described in Section 2.1. Consider the 
problem of excessive NOx emission and lower reheat steam temperature is more severe under lower loads. As a result, only $650 \mathrm{MW}, 800 \mathrm{MW}$, and $850 \mathrm{MW}$ conditions are discussed in the following. Corresponding data are listed in Appendix A (Tables A1-A3) in the Supplementary file.

Remark 2. Reheat steam temperature in the experiment was not controlled by a closed-loop way, and hence, its values are real. Therefore, all collected experimental data are more useful than data collected in practical running way when validating the performance of our method that will be presented later.

\section{Estimations of NOx and Reheat Steam Temperature Based on MO-NPLS with rdCV}

PLS/NPLS algorithms have been applied in engineering (for example, see [12-14]). However, due to the limited number of samples, the prediction accuracy of PLS/NPLS based on traditional k-fold cross validation may decrease. Motivated by this and literature [15], we propose a multiple output version of NPLS (MO-NPLS) model with repeated double crossvalidation ( $\mathrm{rdCV}$ ) strategy in Section 3.1. The predictive model is necessarily used to predict the behaviors of NOx emission and reheat steam temperature and then identify and validate it in different cases of loads in Section 3.2.

3.1. MO-NPLS Model with $r d C V$. Give inputs $x_{i}=\left[x_{i 1}, \ldots, x_{i m}\right]^{\mathrm{T}} \in R^{m}$ and outputs $y_{i}=\left[y_{i 1}, y_{i 2}\right]^{\mathrm{T}} \in R^{2}$ with $i=1, \ldots, n$. Then, let $X=\left[x_{1}, \ldots, x_{n}\right]^{\mathrm{T}} \in R^{n \times m}$ and $Y=\left[y_{1}, \ldots, y_{n}\right] \in R^{n \times 2}$ be the number of $n$ observations for inputs and outputs, respectively. Evidently, $X_{i j}$ indicates the $i$-th observation of the $j$-th input, and this is held on for output $Y$. The superscript " $\mathrm{T}$ " represents transpose. To make the results independent from units, all attributes of data $(X, Y)$ are normalized into range $[-1,1]$ according to the $z$ score rule and are denoted by $\left(E_{0}, F_{0}\right)$ with $E_{0} \in R^{n \times m}$ and $F_{0} \in R^{n \times 2}$.

Define $t_{j} \in R^{n}$ and $u_{j} \in R^{n}(j=1, \ldots, m)$ are the principal components of $X$ and $Y$, respectively. Similarly as traditional nonlinear PLS [16, 17], rdCV-MO-NPLS is in nature a recursive modelling strategy, aiming to establish relationship between $t_{j}$ and $u_{j}(j=1, \ldots, m)$ firstly and then implement the regression relationship of $X$ and $Y$.

Let $u_{1}$ be any column of $F_{0}$ at the beginning. Then, one can estimate of the first components $\left(t_{1}, u_{1}\right)$ as follows.

Firstly, $t_{1}$ is calculated by

$$
t_{1}=\frac{E_{0} w_{1}}{w_{1}^{\mathrm{T}} w_{1}}
$$

where $w_{1} \in R^{m \times 1}$ is the weight of matrix $E_{0}$ and obtained by $w_{1}^{\mathrm{T}}=u_{1}^{\mathrm{T}} E_{0} /\left(u_{1}^{\mathrm{T}} u_{1}\right)$.

Then, one can fit the polynomial relationship between $t_{1}$ and $u_{1}$ by the least squares method. Specifically, assume the relationship between $t_{1}$ and $u_{1}$ is quadratic, namely,

$$
u_{1}=f\left(t_{1}\right)+e_{1}=c_{1,0} I+c_{1,1} t_{1}+c_{1,2} t_{1}^{2}+e_{1},
$$

where $e_{1} \in R^{n}$ is the residual vector which is independent and identically distributed. $I \in R^{n}$ is a vector of ones. Take $Z=\left[I, t_{1}, t_{1}^{2}\right] \in R^{n \times 3}$ and $c_{1}=\left[c_{1,0}, c_{1,1}, c_{1,2}\right]^{\mathrm{T}} \in R^{3}$, then (4) can be rewritten by a compact form:

$$
u_{1}=Z c_{1}+e_{1} \text {. }
$$

So, one can get the polynomial coefficient $c_{1}$ by the least squares method:

$$
c_{1}=\left(Z^{\mathrm{T}} Z\right)^{-1} Z^{\mathrm{T}} u_{1}
$$

where $\left(Z^{\mathrm{T}} Z\right)$ represents the inverse matrix of $\left(Z^{\mathrm{T}} Z\right)$.

After coefficients $c_{1}$ are fitted by formula (6), then $r_{1}$, i.e., the estimate of $u_{1}$, can be calculated by

$$
r_{1}=\widehat{u}_{1}=f\left(t_{1}\right)=c_{1,0} I+c_{1,1} t_{1}+c_{1,2} t_{1}^{2} .
$$

Then, update $u_{1}$ (mark $u_{1 \text {,new }}$ ) by

$$
u_{1, \text { new }}=\frac{F_{0} q_{1}}{q_{1}^{\mathrm{T}} q_{1}}
$$

where $q_{1} \in R^{2 \times 1}$ are weights of matrix $F_{0}$ and determined by $q_{1}^{\mathrm{T}}=r_{1}^{\mathrm{T}} F_{0} /\left(r_{1}^{\mathrm{T}} r_{1}\right)$. Next, $w_{1}$ needs to be updated according to [18].

At this point, we can recalculate the vector $t_{1}$ (mark $\left.t_{1, \text { new }}\right)$ by formula (3) with the updated $w_{1}$.

Check the convergence of $t_{1}$ : if $\left\|t_{1, \text { new }}-t_{1}\right\| /\left\|t_{1}\right\| \geq 10^{-6}$, refit the polynomial coefficient $c_{1}$ between $u_{1 \text {,new }}$ and $t_{1 \text {,new }}$. Otherwise, calculate the regression coefficient $p_{1}$ by

$$
p_{1}^{\mathrm{T}}=\frac{t_{1, \text { new }}^{\mathrm{T}} E_{0}}{t_{1, \text { new }}^{\mathrm{T}} t_{1, \text { new }}} .
$$

Finally, the residual of $E_{0}$ and $F_{0}$ (mark $E_{1}$ and $F_{1}$ ) that will be used in the next iteration can be induced by

$$
\begin{aligned}
& E_{1}=E_{0}-t_{1, \text { new }} p_{1}^{\mathrm{T}}, \\
& F_{1}=F_{0}-r_{1} q_{1}^{\mathrm{T}},
\end{aligned}
$$

with regression coefficient $p_{j}$.

Replace $E_{0}$ and $F_{0}$ with $E_{1}$ and $F_{1}$ and formulas (3)-(10) are repeated until all $m$ principal components $\left(t_{j}, u_{j}\right)$ with $j=1, \ldots, m$ are extracted.

After all $m$ principal components have been extracted, optimum number $a_{\text {final }}\left(a_{\text {final }} \leq m\right)$ can be selected. Usually, $\mathrm{k}$-fold strategy is applied, whereas rdCV strategy is adopted here for achieving more robust predictive ability, which has been proven of PLS in [15]. This is the reason why we call our model rdCV-MO-NPLS. Once $a_{\text {final }}$ is determined, the prediction of outputs $Y$ can thus be obtained according to

$$
\widehat{Y}=\bar{Y}+\left\langle s_{Y}, \sum_{k=1}^{a_{\text {final }}} r_{k} q_{k}^{\mathrm{T}}\right\rangle, \quad k=1, \ldots, a_{\text {final }},
$$

where $\langle\cdot, \cdot\rangle$ means point-product operation of two vectors with equal dimensionality; $\bar{Y}=\left(\bar{Y}_{1}, \bar{Y}_{2}\right)$ with $\bar{Y}_{j}=(1 / n) \sum_{i=1}^{n} Y_{i j}, j=1,2 ; \quad$ and $\quad s_{Y}=\left(s_{Y_{1}}, s_{Y_{2}}\right)$ with $s_{Y_{j}}=\sqrt{(1 / n) \sum_{i=1}^{n}\left(Y_{i j}-\bar{Y}_{j}\right)^{2}}$.

From the above interpretations, the rdCV-MO-NPLS is summarized in Algorithm 1. 
Input: data $(X, Y)$ and parameters $N_{\text {rep }}, \mathrm{SEG}_{\text {test }}, \mathrm{SEG}_{\text {calib }}$;

Output: optimal number of principal component $a_{\text {final }}$ and rdCV-MO-NPLS model.

for rep $=1$ to $N_{\text {rep }}$ do

Split dataset $S$ equally into $S E G_{\text {test }}$ groups, i.e., $S=\left\{S^{(1)}, S^{(2)}, \ldots, S^{\left(\mathrm{SEG}_{\text {test }}\right)}\right\}$;

for $i=1$ to $\mathrm{SEG}_{\text {test }}$ do

Select $S^{(i)}$ as Test set, and construct Calibration sets $S^{(-i)}=S-S^{(i)}$;

Split Calibration set equally into $\mathrm{SEG}_{\text {calib }}$ groups, $S^{(-i)}=\left\{V^{(1)}, V^{(2)}, \ldots, V^{\left(\mathrm{SEG}_{\text {calib }}\right)}\right\}$;

for $j=1$ to $\mathrm{SEG}_{\text {calib }}$ do

Select $V^{(j)}$ as Validation set and $V^{(-j)}=S^{(-i)}-V^{(j)}$ as Training set;

Fit MO-NPLS based on $V^{(-j)}$ with, respectively, $a=1,2, \ldots, m$ of principal components,

Apply the MO-NPLS models to $V^{(j)}$ and get predictive $\widehat{Y}_{j}^{a}$ for $a=1,2, \ldots, m$;

Calculate mean square error $\operatorname{MSE}_{j}^{a}=\left(1 / n_{\mathrm{MSE}}\right) \sum_{k=1}^{n_{\mathrm{MSE}}}\left(Y_{j}(k)-\widehat{Y}_{j}^{a}(k)\right)^{2}$, with the number of objects in the used validation set $n_{\mathrm{MSE}}$ and the output objects of validation set $Y_{j}$;

Estimate optimum principal components $a_{\mathrm{opt}_{1}}^{(i)}, \ldots, a_{\mathrm{opt}_{\mathrm{k}}}^{(i)}$ according to $\hat{Y}^{a}$ based on standard error method [15] (Here, more than one $a_{\mathrm{opt}}$ may be selected (i.e., $k \geq 1$ ) because of different confidence interval);

Make MO-NPLS models based on Calibration set $S^{(-i)}$ with $a=a_{\mathrm{opt}_{1}}^{(i)}, \ldots, a_{\mathrm{opt}_{k}}^{(i)}$;

Test fitted models on $S^{(i)}$ and obtain a group of $k$ predictions $\widehat{Y}_{k}^{a}$ as well as $k$ biases;

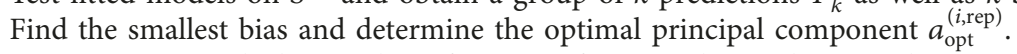

One can get $a_{\mathrm{opt}}$ with the number of SEG test after completing the outer loop.

Totally, after a complete rdCV run, we can get $a_{\text {opt }}$ with the number of $\left(N_{\text {rep }} \times \mathrm{SEG}_{\text {test }}\right)$. The final optimum of principal component $a_{\text {final }}$ is the one with highest frequency in $a_{\text {opt }}^{i \text { rep }}$.

Identify rdCV-MO-NPLS model with database $S$ and $a_{\text {final }}$ to get model parameters $[w, p, c, q]$ based on (3)-(10).

Algorithm 1: rdCV-MO-NPLS.

\subsection{Model Identification and Validation}

3.2.1. Model Identification. In this section, rdCV-MO-NPLS is identified, respectively, at $650 \mathrm{MW}, 800 \mathrm{MW}$, and $850 \mathrm{MW}$. In each case, identification as well as rdCV data are shown in Table A1 (from lines 1 to 45), Table A2 (lines 1 to 30), and Table A3 (lines 1 to 90). In cases of $650 \mathrm{MW}$ and $850 \mathrm{MW}$, six inputs were considered, including C-F level thermal loads $\left(X_{1}\right.$ to $\left.X_{4}, \mathrm{MW}\right)$, running $\mathrm{O}_{2}\left(X_{5}\right)$, and $\alpha_{\mathrm{SOFA}}$ $\left(X_{6}, \%\right)$, whereas seven inputs were considered in $800 \mathrm{MW}$, which are B-F level thermal loads $\left(X_{1}\right.$ to $\left.X_{5}, \mathrm{MW}\right)$, running $\mathrm{O}_{2}\left(X_{6}\right)$, and $\alpha_{\text {SOFA }}\left(X_{7}, \%\right)$. In all cases, the outputs are

$$
Y=\left(\operatorname{NOx}(X), \mathrm{T}_{\mathrm{r}}(X)\right) .
$$

Figure 2 displays the results of applying rdCV. It can be seen that the highest percentage in three cases are, respectively, $0.32\left(a_{\mathrm{opt}}=3\right), 0.38\left(a_{\mathrm{opt}}=2\right)$, and $0.256\left(a_{\mathrm{opt}}=2\right)$. Hence, the final optimum principal component $a_{\text {final }}$ in each case is 3,2 , and 2, respectively. With the help of $a_{\text {final }}$, the rdCV-MO-NPLS model can be identified as Case 1 to Case 3.

For better comparison, 5-fold cross validation (We call 5-fold-MO-NPLS model) is conducted by the same identification data as the rdCV method. After 5-fold cross validation process, the optimum principal component $a_{\text {final }}$ of $650 \mathrm{MW}, 800 \mathrm{MW}$, and $850 \mathrm{MW}$ cases is 4,1 , and 4 , respectively. Then, the validation results of 5-fold-MO-NPLS model with their $a_{\text {final }}$ will be seen in the next section.

Case 1 (rdCV-MO-NPLS of $650 \mathrm{MW}$ load condition). Since $a_{\text {final }}=3$, the first three components $\left(t_{1}, u_{1}\right),\left(t_{2}, u_{2}\right)$, and $\left(t_{3}, u_{3}\right)$ are selected. Normalize the training data presented in Table $\mathrm{A} 1$ (from lines 1 to 45$)$ into $E_{0}=\left(e_{1}, \ldots, e_{6}\right)$ and $F_{0}$ according to $z$-score rule. Corresponding parameters of $(w, p, c, q)$ shown in Table 1 as well as $\left(t_{1}, u_{1}\right),\left(t_{2}, u_{2}\right)$, and $\left(t_{3}, u_{3}\right)$ are identified based on (3)-(11). The rdCV-MO-NPLS predictive model is in form of

$$
\begin{aligned}
t_{1}= & E_{0} w_{1}=E_{0}[0.1084,0.7642,-0.2669,-0.5667, \\
& -0.0943,0.0555]^{\mathrm{T}}, \\
t_{2}= & E_{1} w_{2}=E_{0}\left(I-w_{1} p_{1}^{\mathrm{T}}\right) w_{2}=E_{0}[-0.2094,-0.2329, \\
& -0.6923,-0.7341,-0.1408,0.1400]^{\mathrm{T}}, \\
t_{3}= & E_{2} w_{3}=E_{0}\left(I-w_{1} p_{1}^{\mathrm{T}}\right)\left(I-w_{2} p_{2}^{\mathrm{T}}\right) w_{3}=E_{0}[0.8325, \\
& -0.4500,0.1520,1.2745,0.0707,-0.0796]^{\mathrm{T}}, \\
f= & r_{1} q_{1}^{\mathrm{T}}+r_{2} q_{2}^{\mathrm{T}}+r_{3} q_{3}^{\mathrm{T}}=\left[-0.1112+1.9943 t_{1}+0.6504 t_{1}^{2}\right. \\
& +0.626 t_{2}+0.3445 t_{2}^{2}+0.2332 t_{3}-0.4783 t_{3}^{2},-0.0403 \\
& +1.9161 t_{1}+0.6248 t_{1}^{2}-0.9299 t_{2}-0.5116 t_{2}^{2}+0.1726 t_{3} \\
& \left.-0.3540 t_{3}^{2}\right] \\
:= & {\left[f_{1}, f_{2}\right], } \\
\widehat{Y}= & {\left[\widehat{Y}_{1}, \widehat{Y}_{2}\right]=\left[\bar{Y}_{1}, \bar{Y}_{1}\right]+\left\langle\left[s_{Y 1}, s_{Y 2}\right],\left[f_{1}, f_{2}\right]\right\rangle } \\
= & {\left[509.5+55.8445 f_{1}, 581.2+6.1878 f_{2}\right] . }
\end{aligned}
$$

Case 2 (rdCV-MO-NPLS of $800 \mathrm{MW}$ load condition). The first two components $\left(t_{1}, u_{1}\right)$ and $\left(t_{2}, u_{2}\right)$ are chosen. Based on data as shown in Table A2 (lines 1 to 30 ), and identified 


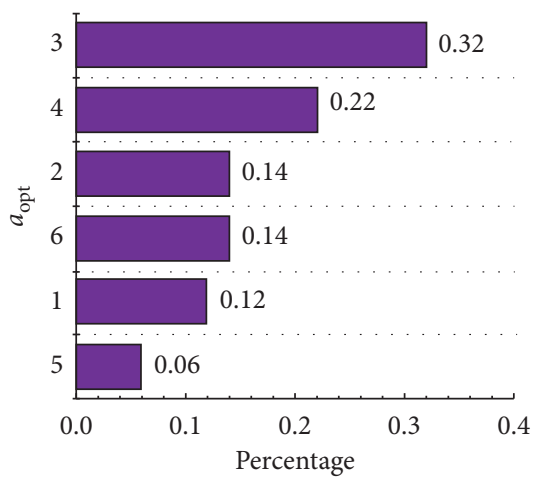

(a)

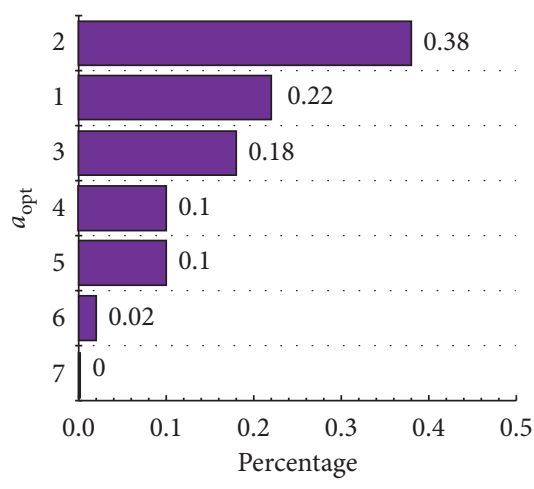

(b)

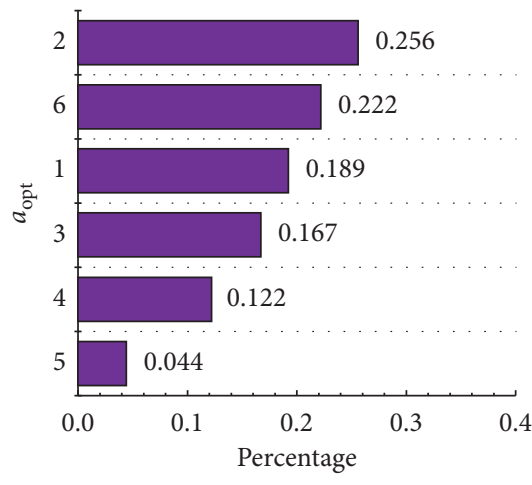

(c)

FIgURe 2: Percentage of principal components $a_{\mathrm{opt}}$ : (a) $650 \mathrm{MW}$, (b) $800 \mathrm{MW}$, and (c) $850 \mathrm{MW}$.

parameters of rdCV-MO-NPLS shown in Table 2, the rdCVMO-NPLS model can be established as

$$
\begin{aligned}
t_{1}= & E_{0} w_{1}=E_{0}[-0.4416,-0.3083,0.3598,-0.1139 \\
& -0.1758,-0.5304,-0.5053]^{\mathrm{T}}, \\
t_{2}= & E_{1} w_{2}=E_{0}\left(I-w_{1} p_{1}^{\mathrm{T}}\right) w_{2}=E_{0}[0.4468,0.0730,-0.3284 \\
& -0.0332,0.3795,0.4261,0.6668]^{\mathrm{T}}, \\
f= & r_{1} q_{1}^{\mathrm{T}}+r_{2} q_{2}^{\mathrm{T}}=\left[-0.1626+1.104 t_{1}+0.2081 t_{1}^{2}\right. \\
& +0.2959 t_{2}+0.0180 t_{2}^{2},-0.1275+0.9698 t_{1}^{2}+0.1828 t_{1} \\
& \left.-0.3007 t_{2}-0.0183 t_{2}^{2}\right] \\
:= & {\left[f_{1}, f_{2}\right], } \\
\widehat{Y}= & {\left[\widehat{Y}_{1}, \widehat{Y}_{2}\right]=\left[\bar{Y}_{1}, \bar{Y}_{2}\right]+\left\langle\left[s_{Y 1}, s_{Y 2}\right],\left[f_{1}, f_{2}\right]\right\rangle } \\
= & {\left[451.9+27.3115 f_{1}, 585.7+4.7006 f_{2}\right] . }
\end{aligned}
$$

Case 3 (rdCV-MO-NPLS of $850 \mathrm{MW}$ load condition). Similar as Case 2, the first two components $\left(t_{1}, u_{1}\right)$ and $\left(t_{2}\right.$, $u_{2}$ ) were selected on the basis of Table A3 (from lines 1-90). Additionally, identified parameters of rdCV-MO-NPLS are shown in Table 3. The rdCV-MO-NPLS model is

$$
\begin{aligned}
t_{1}= & E_{0} w_{1}=E_{0}[0.2595,0.4561,-0.3307,-0.5786, \\
& -0.0490,0.5273]^{\mathrm{T}}, \\
t_{2}= & E_{0}\left(I-w_{1} p_{1}^{T}\right) w_{2}=E_{0}[0.4214,0.4823,0.2326, \\
& -1.2139,0.0331,0.0308]^{\mathrm{T}}, \\
f= & r_{1} q_{1}^{\mathrm{T}}+r_{2} q_{2}^{\mathrm{T}}=\left[0.0143+1.3261 t_{1}+0.0230 t_{1}^{2}+0.5570 t_{2}\right. \\
& -0.0635 t_{2}^{2}, 0.0049+0.7791 t_{1}-0.0135 t_{1}^{2}-0.9594 t_{2} \\
& +0.1095 t_{2}^{2} \\
& :=\left[f_{1}, f_{2}\right], \\
\widehat{Y}= & {\left[\widehat{Y}_{1}, \widehat{Y}_{2}\right]=\left[\bar{Y}_{1}, \bar{Y}_{2}\right]+\left\langle\left[s_{Y 1}, s_{Y 2}\right],\left[f_{1}, f_{2}\right]\right\rangle } \\
= & {\left[464.2+35.8762 f_{1}, 594.8+2.9182 f_{2}\right] . }
\end{aligned}
$$

3.2.2. Model Validation. In general, generalization ability of a prediction model is more important than its fitting ability. Therefore, it is necessary to validate aforementioned models to get their generalization ability. Validation samples in three cases are seen in Table A1 (from lines 46 to 53), Table A2 (from lines 31 to 36), and Table A3 (from lines 91 to 96) in Supplementary file, respectively.

To state the superiority of the rdCV-MO-NPLS model, another three well-known methods: 5-fold-MO-NPLS, support vector regression (SVR), and artificial neural network (ANN) are employed to establish models of NOx emission and reheated steam temperature. All methods are on the same identification and validation data. Figures 3-5 show the predictive results for different methods. The prediction error sum (PRESS $=\sum_{i=1}^{n_{\text {PRESS }}}\left|\widehat{Y}_{i}-Y_{i}\right| / Y_{i}$ with prediction sample number $n_{\text {PRESS }}$ ) representing generalization ability and simulation error sum (SS $=\sum_{i=1}^{n_{S S}} \mid \widehat{Y}_{i}-$ $Y_{i} \mid / Y_{i}$ with simulation sample number $n_{\text {PRESS }}$ ) reflecting approximate ability is presented in Table 4 .

It can be seen from Figures 3-5 that the prediction of rdCV-MO-NPLS approaches the real values the most while the deviation among 5-fold-MO-NPLS, SVR, or ANN and real value is larger in the three working load conditions. Furthermore, from Table 4, it can be concluded that the PRESS value of rdCV-MO-NPLS are lower than the other three methods in all the three cases, which means rdCVMO-NPLS has stronger predictive capability. This verified that firstly, rdCV can achieve more robust ability than the k-fold strategy; secondly, SVR can only establish the SISO model, as the boiler combustion system is strongly coupled, so the accuracy of predictive model will be reduced due to decoupling. Finally, as for ANN, it can deal with the MIMO system but is prone to overfitting easily.

Remark 3. Compared with $\mathrm{k}$-fold cross validation, $\mathrm{rdCV}$ can achieve more robust ability. This also shows that rdCV can be successfully used in NPLS. Besides, rdCV-MO-NPLS is more powerful than SVR and ANN in generalization ability on the modelling of NOx emission and reheat steam temperature. 
TABLE 1: Parameters of rdCV-MO-NPLS model at $650 \mathrm{MW}$.

\begin{tabular}{|c|c|c|c|c|}
\hline$h_{1}$ & $\begin{array}{c}w_{1} \\
0.1084 \\
0.7642 \\
-0.2669 \\
-0.5667 \\
-0.0943 \\
0.0555 \\
\end{array}$ & $\begin{array}{c}p_{1} \\
-1.0821 \\
1.7506 \\
-2.0513 \\
1.7544 \\
-1.3794 \\
1.7356 \\
\end{array}$ & $\begin{array}{c}c_{1} \\
-0.2037 \\
2.7657 \\
0.9019\end{array}$ & $\begin{array}{c}q_{1} \\
0.7211 \\
0.6928\end{array}$ \\
\hline$h_{2}$ & $\begin{array}{c}w_{2} \\
-0.2521 \\
-0.5344 \\
-0.5870 \\
-0.5105 \\
0.1779 \\
0.1181\end{array}$ & $\begin{array}{c}p_{2} \\
1.3719 \\
-1.1655 \\
0.1064 \\
-1.2466 \\
0.0342 \\
1.2109\end{array}$ & $\begin{array}{c}c_{2} \\
-0.0598 \\
1.1211 \\
0.6167\end{array}$ & $\begin{array}{c}q_{2} \\
0.5585 \\
-0.8295\end{array}$ \\
\hline$h_{3}$ & $\begin{array}{c}w_{3} \\
0.7658 \\
-0.0421 \\
-0.5367 \\
0.3318 \\
0.0995 \\
0.0608\end{array}$ & $\begin{array}{c}p_{3} \\
1.7521 \\
-0.7898 \\
0.0805 \\
-0.6007 \\
-1.1659 \\
-0.2728\end{array}$ & $\begin{array}{c}c_{3} \\
0.0860 \\
0.2901 \\
-0.5950\end{array}$ & $\begin{array}{c}q_{3} \\
0.8038 \\
0.5949\end{array}$ \\
\hline
\end{tabular}

TABle 2: Parameters of rdCV-MO-NPLS model at $800 \mathrm{MW}$.

\begin{tabular}{ccccc}
\hline & $w_{1}$ & $p_{1}$ & $c_{1}$ & $q_{1}$ \\
& -0.4416 & -0.0237 & -0.2057 & 0.7513 \\
& -0.3083 & -0.2094 & 1.4695 & 0.6600 \\
$h_{1}$ & 0.3598 & 0.0880 & 0.2770 & \\
& -0.1139 & 0.2170 & & \\
& -0.1758 & -0.0283 & & \\
& -0.5304 & -1.0054 & & \\
& 0.5053 & 0.7517 & & $q_{2}$ \\
& $w_{2}$ & $p_{2}$ & $c_{2}$ & 0.7014 \\
& 0.3187 & 0.9644 & -0.0116 & \\
& -0.0164 & 0.1064 & 0.4219 & -0.7128 \\
$h_{2}$ & -0.2241 & -0.2031 & 0.0257 & \\
& -0.0662 & -0.4456 & & \\
& 0.3286 & -0.9193 & & \\
& 0.2724 & 0.3618 & & \\
& 0.8133 & 1.0018 & & \\
& & & &
\end{tabular}

TABLE 3: Parameters of rdCV-MO-NPLS model at $850 \mathrm{MW}$.

\begin{tabular}{|c|c|c|c|c|}
\hline & $\begin{array}{c}w_{1} \\
0.2595\end{array}$ & $\begin{array}{c}p_{1} \\
0.3142\end{array}$ & $\begin{array}{c}c_{1} \\
0.0113\end{array}$ & $\begin{array}{c}q_{1} \\
0.8622\end{array}$ \\
\hline & 0.4561 & 0.0651 & 1.5380 & 0.5066 \\
\hline \multirow[t]{7}{*}{$h_{1}$} & -0.3307 & -0.6749 & -0.0266 & \\
\hline & -0.5786 & 0.0298 & & \\
\hline & -0.0490 & -0.2947 & & \\
\hline & 0.05273 & 1.2676 & & \\
\hline & $w_{2}$ & $p_{2}$ & $c_{2}$ & $q_{2}$ \\
\hline & 0.1698 & -1.6923 & 0.0092 & 0.5021 \\
\hline & 0.0401 & -2.2468 & 1.1094 & -0.8648 \\
\hline \multirow[t]{4}{*}{$h_{2}$} & 0.5532 & -0.5951 & -0.1266 & \\
\hline & -0.6529 & -2.4330 & & \\
\hline & 0.0806 & -0.2785 & & \\
\hline & -0.4804 & -0.2926 & & \\
\hline
\end{tabular}

\section{Combustion Optimization}

Artificial bee colony $(\mathrm{ABC})$ is a well-known intelligent optimization algorithm proposed in 2005 [19]. It has been applied more and more on engineering optimization in recent years [20-23] because of its simplicity to implement as it uses fewer control parameters [24, 25] and robust ability to get out of a local minimum [26]. In this section, a multiobjective version of $\mathrm{ABC}(\mathrm{MO}-\mathrm{ABC})$ [25] is used to optimize NOx emission and reheat steam temperature.

4.1. Joint Optimization via Multiobjective Artificial Bee Colony Algorithm. The objective of combustion optimization is to minimize NOx emission and maximize reheat steam temperature (Tr) through searching optimal inputs $(x)$ which is $m$-dimensional, namely, thermal loads $\left(Q_{i}\right)$, running $\mathrm{O}_{2}$, and $\alpha_{\text {SOFA }}$ based on rdCV-MO-NPLS models established in Section 3. Considering that these two objectives are contradictory, we can only find a set of nondominated solutions. Objective function can be described as follows:

$$
\begin{array}{ll}
\min _{x} & Y=\left[Y_{1}(x), Y_{2}(x)\right], \\
\text { s.t. } & X_{\min } \leq x \leq X_{\max }, i=1, \ldots, m,
\end{array}
$$

where $Y_{1}(x)$ is the NOx emission. $Y_{2}(x)$ is the inverse of $\operatorname{Tr}$ by converting the problem of maximizing $\operatorname{Tr}$ to minimize its inverse. The values of $Y_{1}(x)$ and the inverse of $Y_{2}(x)$ of $650 \mathrm{MW}, 800 \mathrm{MW}$, and $850 \mathrm{MW}$ can be calculated from formulas (13)-(15), respectively. $X_{\min }=\left[X_{\min , 1}, \ldots\right.$, $\left.X_{\min , m}\right]^{\mathrm{T}} \in R^{m}$ and $X_{\max }=\left[X_{\max , 1}, \ldots, X_{\max , m}\right]^{\mathrm{T}} \in R^{m}$ are the lower and upper bounds of inputs in the rdCV-MONPLS model.

To solve problem 4.1, a MO-ABC is applied step by step as follows:

Step 1 (solutions initialization). New variables named $N p$ and FoodNumber will be defined as the population size and the number of food sources, respectively. Since each employed bee represents a food source and the number of employed bees and onlooker bees is equal, the FoodNumber can be set to half of the population (i.e., $N$ p/2) [25]. Each food source will be initialized through a function randomly generated in input space according to

$$
x_{i d}=X_{\min , d}+\operatorname{rand}[0,1]\left(X_{\max , d}-X_{\min , d}\right),
$$

where $i$ is the index of the food source with the range of $i=1,2, \ldots$, FoodNumber; $d$ is the dimension index of each food source with the range of $d=1,2, \ldots, m$; rand $[0,1]$ is a random number distributed uniformly over the interval $[0,1]$; and $X_{\min , d}$ and $X_{\max , d}$ are the lower and upper bounds of the $d$ th dimension, respectively.

In addition, assign each food source with a trial index trial $_{i}, i=1,2, \ldots$, FoodNumber $_{\text {; }}$ trial $_{i}$ is initialized to 0 for each food source.

Step 2 (solutions evolve in employed bee phase). The initial solutions in (17) first evolved through the help of employed bees according to 

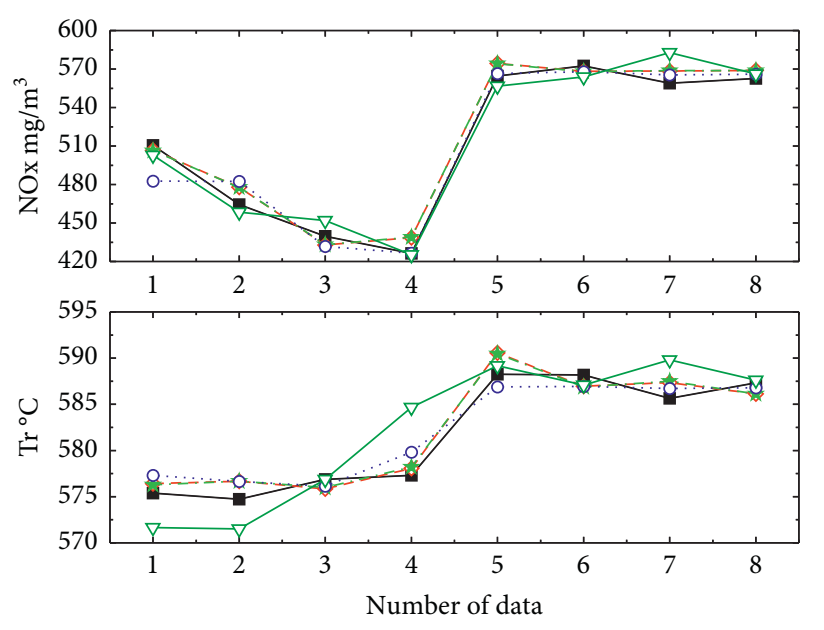

$$
\begin{array}{ll}
\rightarrow-\text { Experimental data } & \cdots 0 . \text { SVR } \\
-\diamond-\text { rdCV-MO-NPLS } & \rightarrow-\text { ANN } \\
\star-5 \text {-fold-MO-NPLS } &
\end{array}
$$

FIgURE 3: Comparisons among different predictors at $650 \mathrm{MW}$.

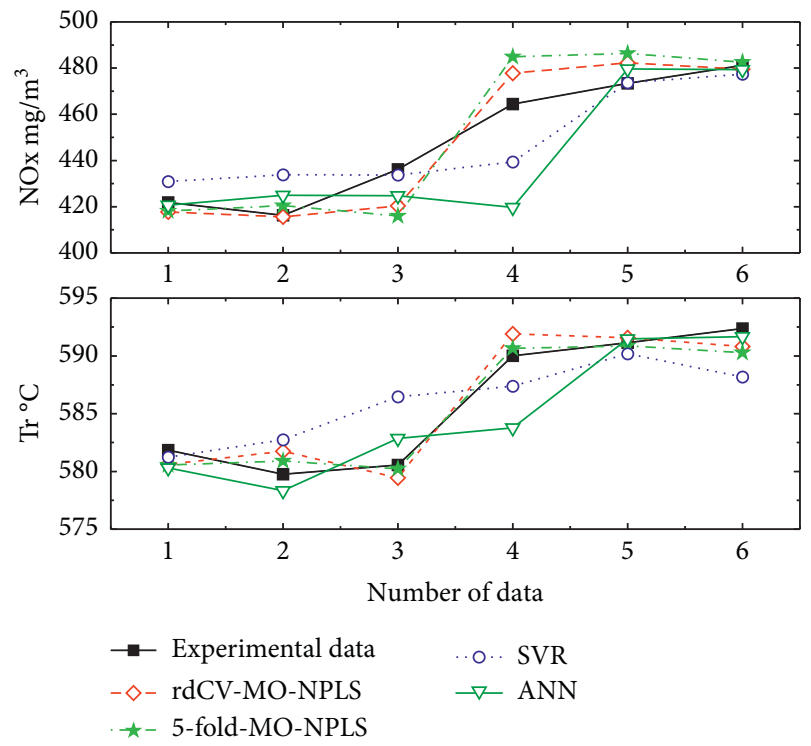

FIgURE 4: Comparisons among different predictors at $800 \mathrm{MW}$.

$$
v_{i, d}=x_{i, d}+\phi_{i, d} \cdot\left(x_{i, d}-x_{k, d}\right),
$$

where $k \neq i$ and $k=1,2, \ldots$, FoodNumber and $d=1,2, \ldots, m . \phi_{i, d}$ is a random number distributed uniformly between $[-1,1]$. If $v_{i}$ dominates $x_{i}$, i.e., $\operatorname{NOx}\left(v_{i}\right) \leq \operatorname{NOx}\left(x_{i}\right)$ and $\left(1 / \operatorname{Tr}\left(v_{i}\right)\right) \leq\left(1 / \operatorname{Tr}\left(x_{i}\right)\right)$ (denoted as $\left.v_{i} \prec x_{i}\right)$, update $x_{i}$ to $v_{i}$. If not, the update was unsuccessful, the trial for the old food source, $x_{i}$, is incremented by one.

Step 3 (solutions evolve in onlooker bee phase). The quality of solution $x_{i}$, i.e., fitness of solution $x_{i}$, is evaluated by
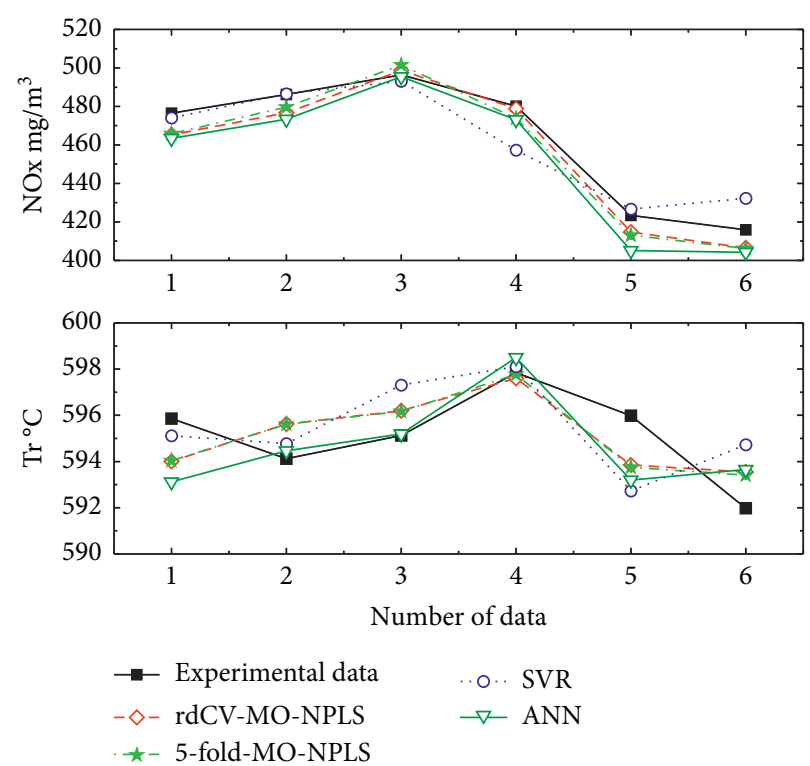

Figure 5: Comparisons among different predictors at $850 \mathrm{MW}$.

$$
\text { fit }_{i}=\frac{\operatorname{dom}\left(x_{i}\right)}{\text { FoodNumber }}
$$

where $\operatorname{dom}\left(x_{i}\right)$ is the number of solutions that are dominated by food source $x_{i}$. The probability for each food source $x_{i}$ advertised by the corresponding employed bee will be calculated in a roulette way according to

$$
P_{i}=\frac{\text { fit }_{i}}{\sum_{k=1}^{\text {FoodNumber }} \text { fit }_{k}} .
$$

Once a solution is selected, this solution will evolve to a new position according to formula (18) if this new position dominates its previous one. Otherwise, its trial value is increased by one.

Step 4 (solutions evolve in scout bee phase). There is at most one scout bee in the colony. This means if the maximal trial value in the colony reaches the limit, then the corresponding food source will turn to a scout bee and after doing a random search according to formula (17). At the same time, its trial value will be reset to zero. The limit is determined by

$$
\text { limit }=\frac{N \mathrm{p}}{2} \cdot m
$$

Step 5 (solution archive updates). A fixed-size archive (e.g., FoodNumber) is conserved to hold the best solutions. Specifically, after the $(t)$ th cycle, we can get the nondominated solutions. Combine them with solutions which are held in archive at $(t-1)$ th cycle. Then, select the top FoodNumber solutions by nondomination strategy to update archive.

All the above steps are repeated until the maximum iteration, Cmax, is met. The main process of $\mathrm{MO}-\mathrm{ABC}$ is summarized in Figure 6.

Remark 4. The specific values of $X_{\min }$ and $X_{\max }$ are shown in Appendix B (Tables B1-B3) in Supplementary part, and it is determined by history running and experimental data as well 
TABLE 4: PRESS and SS values in different methods at $650 \mathrm{MW}, 800 \mathrm{MW}$, and $850 \mathrm{MW}^{1,2}$.

\begin{tabular}{|c|c|c|c|c|c|c|c|}
\hline Loads & Methods & PRESS $_{\text {NOx }}$ & PRESS $_{\text {Tr }}$ & PRESS & $\mathrm{SS}_{\mathrm{NOx}}$ & $\mathrm{SS}_{\mathrm{Tr}}$ & SS \\
\hline \multirow{4}{*}{$650 \mathrm{MW}$} & rdCV-MO-NPLS & 0.1346 & 0.0193 & 0.1539 & 0.8458 & 0.1138 & 0.9596 \\
\hline & 5-fold-MO-NPLS & 0.1354 & 0.0192 & 0.1546 & 0.8458 & 0.1138 & 0.9596 \\
\hline & SVR & 0.1407 & 0.0294 & 0.1701 & 0.8705 & 0.1347 & 1.0052 \\
\hline & ANN & 0.1360 & 0.0336 & 0.1696 & 0.7806 & 0.1342 & 0.9148 \\
\hline \multirow{4}{*}{$800 \mathrm{MW}$} & rdCV-MO-NPLS & 0.0985 & 0.0140 & 0.1125 & 0.5368 & 0.1139 & 0.6507 \\
\hline & 5-fold-MO-NPLS & 0.1397 & 0.0098 & 0.1495 & 0.5368 & 0.1139 & 0.6507 \\
\hline & SVR & 0.1318 & 0.0295 & 0.1613 & 1.3079 & 0.1580 & 1.4659 \\
\hline & ANN & 0.1633 & 0.0214 & 0.1847 & 1.1438 & 0.2416 & 1.3854 \\
\hline \multirow{4}{*}{$850 \mathrm{MW}$} & rdCV-MO-NPLS & 0.0931 & 0.0141 & 0.1072 & 2.4469 & 0.2517 & 2.6986 \\
\hline & 5-fold-MO-NPLS & 0.1068 & 0.0136 & 0.1204 & 2.4469 & 0.2517 & 2.6986 \\
\hline & SVR & 0.1073 & 0.0165 & 0.1238 & 2.5070 & 0.1665 & 2.6735 \\
\hline & ANN & 0.1416 & 0.0139 & 0.1555 & 2.9540 & 0.2784 & 3.2324 \\
\hline
\end{tabular}

${ }^{1}$ The values in bold are the optimal in their columns. ${ }^{2} \mathrm{PRESS}=\mathrm{PRESS}_{\mathrm{NOx}}+\mathrm{PRESS}_{\mathrm{Tr}}$;S $=\mathrm{SS}_{\mathrm{NOx}}+\mathrm{SS}_{\mathrm{Tr}}$.

as security conditions as the usual practice of data-driven methods (for example, see work [4]).

4.2. Optimizing Results and Analysis. To implement MO$\mathrm{ABC}$ as shown above, some parameters should be preset including $N$ p and limit. Here, $N p$ was set to 100 by a trivial way. limit was set to 300 (at $650 \mathrm{MW}$ and $850 \mathrm{MW}$ ) and 350 (at $800 \mathrm{MW}$ ), respectively, based on formula (21).

Furthermore, another popular multiobjective EA (MOEA), NSGA-II, is also conducted for comparison. Values of $N p$ and $\left[X_{\min }, X_{\max }\right.$ ] in NSGA-II are set the same as MO-ABC.

In the present work, we use the number of function evaluations (FEs) as a measure criterion to determine Cmax. Set that both algorithms are terminated after 100,000 FEs. Define $\mathrm{Cmax}_{\mathrm{NSGA}-\mathrm{II}}$ and $\mathrm{Cmax}_{\mathrm{MO}-\mathrm{ABC}}$ as the maximum iteration of NSGA-II and MO-ABC algorithms, respectively. Since $\mathrm{FEs}_{\mathrm{NSGA}-\mathrm{II}}=\mathrm{Np} * \mathrm{Cmax}_{\mathrm{NSGA}-\mathrm{II}}=100 * \mathrm{Cmax}_{\mathrm{NSGA}-\mathrm{II}}=$ 100,000 , then we can get $\mathrm{Cmax}_{\mathrm{NSGA}-\mathrm{II}}=1000$. In addition, the upper bound of the fitness evaluations in basic $\mathrm{ABC}$ is defined and given as $\mathrm{FEs} \leq(\mathrm{SN}+\mathrm{SN}+1) * \mathrm{Cmax}_{\mathrm{MO}-\mathrm{ABC}}+\mathrm{SN}$. In each iteration, there are $\mathrm{SN}$ employed bees, $\mathrm{SN}$ onlooker bees, and at most 1 scout bee [27]. In this paper, substitute "SN $=N \mathrm{p} / 2=50$, FEs $\leq 100,000$ " into above equation, then we can get $\mathrm{Cmax}_{\mathrm{MO}-\mathrm{ABC}}=990$.

The optimization results of MO-ABC and NAGA-II are presented in Figures 7-9.

To assess the solution sets shown in Figures 7-9, a comprehensive quality indicator (QI), i.e., hypervolume (HV) [28], is applied here. The HV indicator represents the volume of the area enclosed by solution set and a reference point, which can combine the quality of convergence, spread, cardinality, and uniformity of solution set and can be defined as follows.

Given a solution set $A$ and a reference point $\mathbf{r}, \mathrm{HV}$ can be calculated as

$$
\mathrm{HV}(A)=\lambda\left(\bigcup_{a \in A}\{x \mid a<x<\mathbf{r}\}\right),
$$

where $\lambda$ is the Lebesgue measure. Put it simply, the HV value of a set can be seen as the volume of the union of the

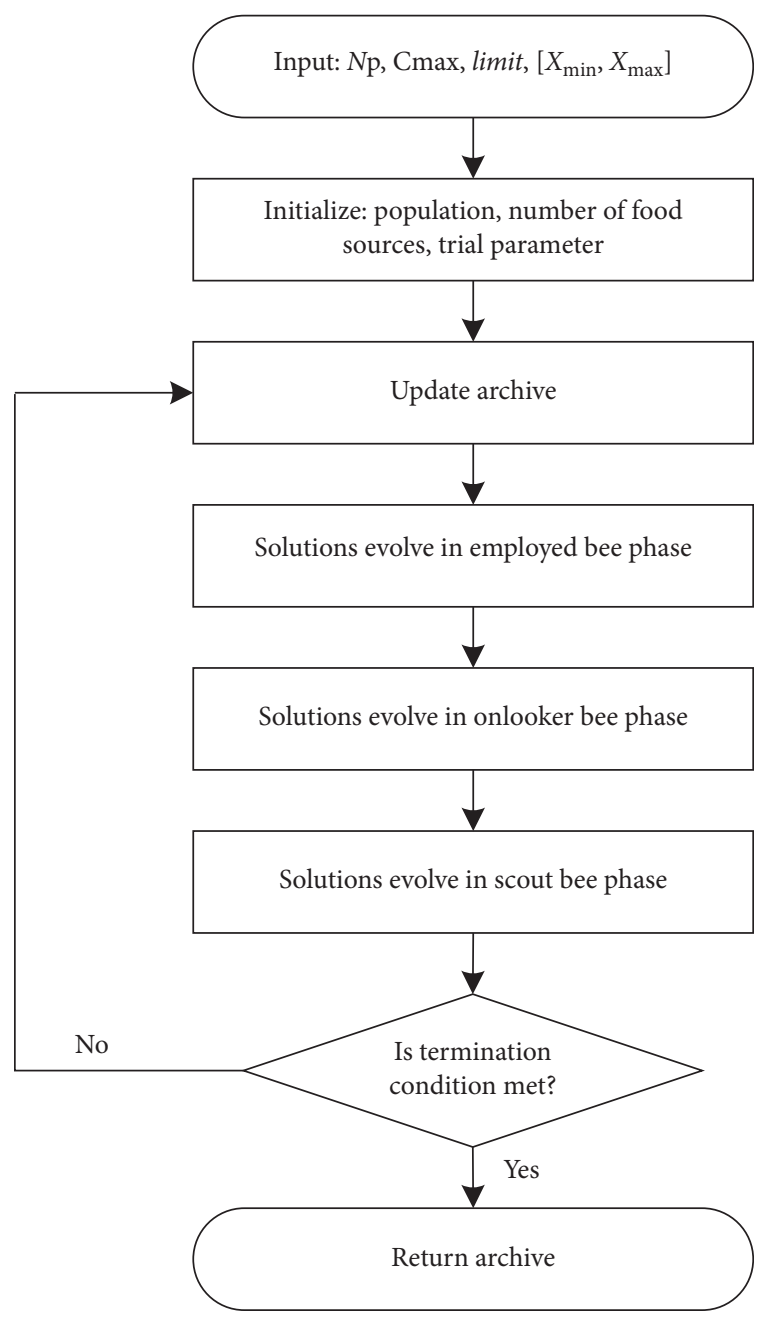

FIgURE 6: Schematic diagram of the MO-ABC algorithm.

hypercubes determined by each of its solutions and the reference point (as the left-bottom vertex and the right-top vertex, respectively).

Specifically, for a two-objective optimization problem, HV can be calculated by the following steps. Firstly, the nondominated points in set $A$ are sorted by descending 
order on their first dimensional objective values. And then, $\mathrm{HV}$ is calculated by

$$
\mathrm{HV}(A)=\sum_{i=1}^{n}\left|\mathrm{obj}_{2}\left(p_{i}\right)-\mathrm{obj}_{2}(\mathbf{r})\right| \cdot\left|\mathrm{obj}_{1}\left(p_{i}\right)-\mathrm{obj}_{1}\left(p_{i-1}\right)\right|
$$

where obj ${ }_{i}\left(p_{j}\right)$ represents the value of the $j$ th solution in $A$ on their $i$ th dimensional objective. $\mathrm{obj}_{1}\left(p_{0}\right)$ is set to $\mathrm{obj}_{1}(\mathbf{r})$. $n$ is the number of solutions in set $A$.

The $\mathbf{r}$ and $\mathrm{HV}$ are illustrated in the third and fourth column of Table 5 .

Table 5 shows that the $\mathrm{HV}$ indicators of $\mathrm{MO}-\mathrm{ABC}$ are higher than NSGA-II in all three load conditions. That is, the solution sets of MO-ABC all outperform NSGA-II (illustrated in Figures 7-9) in the comprehensive performance with comparable time consumption (shown in the last column of Table 5). This means MO-ABC is more applicable to boiler combustion optimization than NSGA-II.

Furthermore, we can present our findings in our current study whether the nondominated solutions by MO-ABC shown in Figures 7-9 are better than real values (i.e., experimental values). Among them, six recommended nondominated solutions with "+" (the principle of selecting these recommended nondominated solutions is to keep NOx as low as possible while maintaining the reheat steam temperature above its designed value) are shown in Tables 6-8 (No. 1-6) as well as the experiment values of $\mathrm{NOx}$ emission and reheat steam temperature (No. 7).

In order to quantify the degree of reduction of $\mathrm{NOx}$ and increase of $\mathrm{Tr}$ relative to the experimental value, percentage improvement $\left(P_{\mathrm{NOx}}\right.$ and $\left.P_{\mathrm{Tr}}\right)$ are defined as follows:

$$
\begin{aligned}
P_{\mathrm{NOx}} & =\frac{\left|\mathrm{NOx}_{M}-\mathrm{NOx}_{e}\right|}{\mathrm{NOx}_{e}} \times 100 \%, \\
P_{\mathrm{Tr}} & =\frac{\left|\operatorname{Tr}_{M}-\mathrm{Tr}_{e}\right|}{\operatorname{Tr}_{e}} \times 100 \%,
\end{aligned}
$$

where $\mathrm{NOx}_{M}$ and $\mathrm{NOx}_{e}$ are the $\mathrm{NOx}$ values obtained by MO-ABC and experiment, respectively. $\operatorname{Tr}_{M}$ and $\operatorname{Tr}_{e}$ are $\mathrm{Tr}$ values obtained by MO-ABC and experiment, respectively. Results are shown in the last two columns of Tables 6-8.

By comparing results in Figures 7-9 and Tables 6-8, we can conclude that optimal $\mathrm{NOx}$ emission and reheat steam temperature achieved by MO-ABC is better than that explored directly from experimental ones (i.e., real data) based on the percentage improvement. This verified that our new viewpoint on combustion optimization is meaningful. To this end, joint optimization of $\mathrm{NOx}$ emission and reheat steam temperature can bring much more benefits to the combustion system with the points of synthetic optimization view.

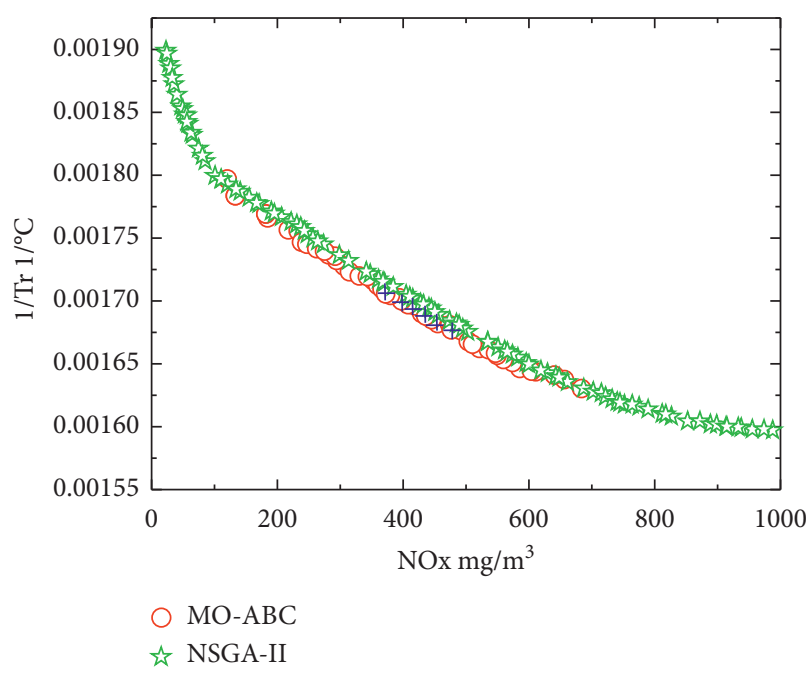

Figure 7: Pareto frontier by MOEAs at $650 \mathrm{MW}$.

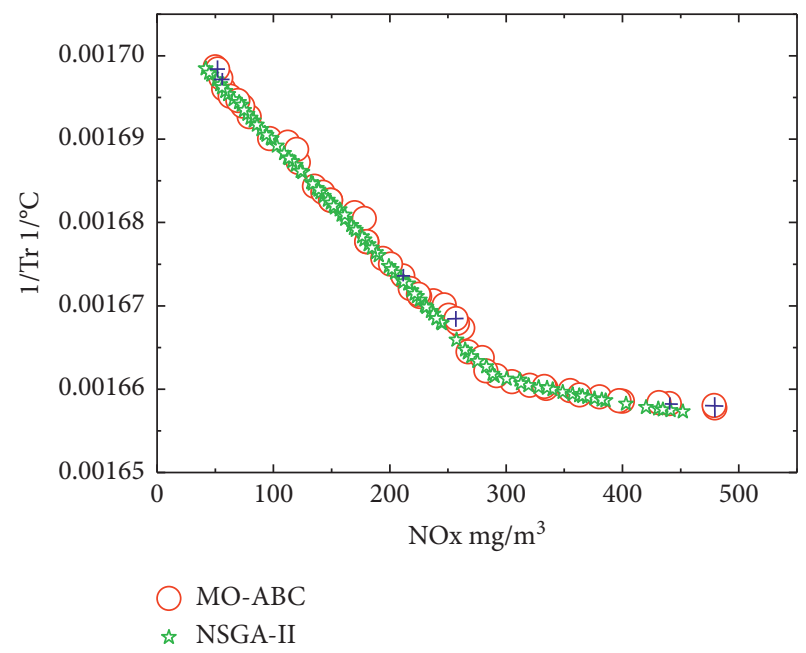

Figure 8: Pareto frontier by MOEAs at $800 \mathrm{MW}$.

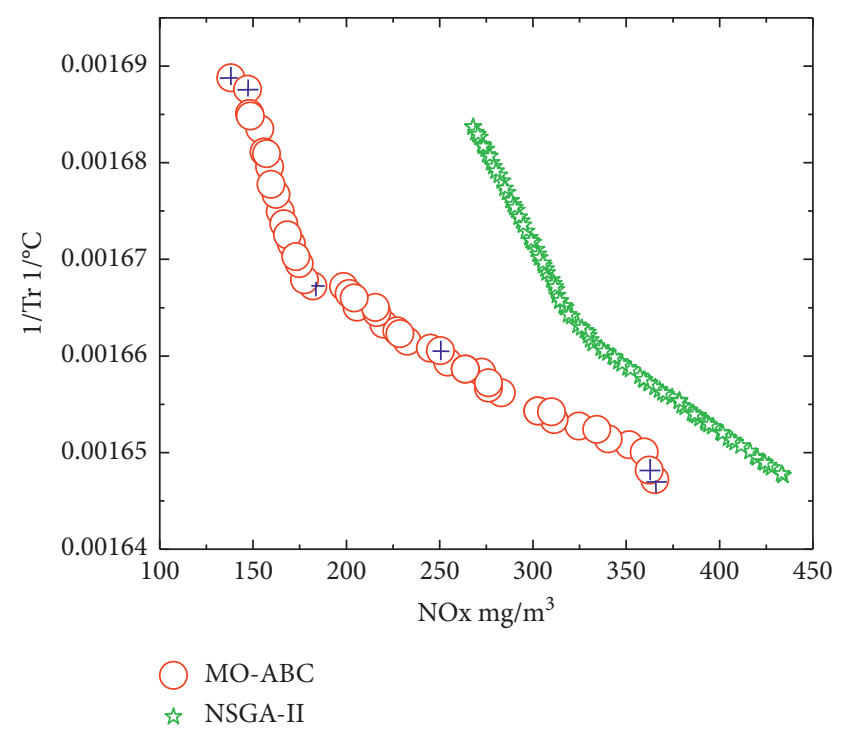

Figure 9: Pareto frontier by MOEAs at $850 \mathrm{MW}$. 
TABLE 5: HV indicator and time consumption by MOEAs.

\begin{tabular}{lcccc}
\hline Loads & MOEAs & $\mathbf{r}$ & HV & Time consuming $(s)$ \\
\hline \multirow{2}{*}{$650 \mathrm{MW}$} & MO-ABC & $(1200,0.002)$ & $\mathbf{0 . 3 5 7 4}$ & 36.503 \\
& NSGA-II & $(1200,0.002)$ & $\mathbf{0 . 2 8 9 2}$ & 37.021 \\
\hline \multirow{2}{*}{$800 \mathrm{MW}$} & MO-ABC & $(500,0.002)$ & $\mathbf{0 . 1 4 8 1}$ & 38.105 \\
& NSGA-II & $(500,0.002)$ & $\mathbf{0 . 1 0 6 2}$ & 37.929 \\
\multirow{2}{*}{$850 \mathrm{MW}$} & MO-ABC & $(500,0.002)$ & $\mathbf{0 . 1 2 3 9}$ & 30.856 \\
& NSGA-II & $(500,0.002)$ & $\mathbf{0 . 0 5 9 0}$ & 29.499 \\
\hline
\end{tabular}

TABLE 6: Recommended setpoints for inputs at $650 \mathrm{MW}$.

\begin{tabular}{|c|c|c|c|c|c|c|c|c|c|c|}
\hline No. & NOx & $\operatorname{Tr}$ & Thermal load (C) & Thermal load (D) & Thermal load (E) & Thermal load (F) & $\alpha_{\mathrm{SOFA}}$ & Running $\mathrm{O}_{2}$ & $P_{\mathrm{NOx}}$ & $P_{\mathrm{Tr}}$ \\
\hline 1 & 416.2 & 578.6 & 146.6 & 167.5 & 154.7 & 205.8 & 0.225 & 4.805 & 6.26 & 0.28 \\
\hline 2 & 436.6 & 580.4 & 143.8 & 171.0 & 150.0 & 209.9 & 0.209 & 4.742 & 1.67 & 0.59 \\
\hline 3 & 403.2 & 577.1 & 146.6 & 167.6 & 155.9 & 205.7 & 0.229 & 4.672 & 9.19 & 0.02 \\
\hline 4 & 427.8 & 579.2 & 146.6 & 171.3 & 147.1 & 209.4 & 0.190 & 4.782 & 3.65 & 0.38 \\
\hline 5 & 441.3 & 581.7 & 140.1 & 169.5 & 147.1 & 210.0 & 0.203 & 4.791 & 0.61 & 0.81 \\
\hline 6 & 439.5 & 582.2 & 142.1 & 170.4 & 147.1 & 209.2 & 0.211 & 4.423 & 1.01 & 0.90 \\
\hline 7 & 444 & 577 & & & & & & & & \\
\hline
\end{tabular}

TABLE 7: Recommended setpoints for inputs at $800 \mathrm{MW}$.

\begin{tabular}{|c|c|c|c|c|c|c|c|c|c|c|c|}
\hline No. & NOx & $\operatorname{Tr}$ & $\begin{array}{l}\text { Thermal load } \\
\text { (B) }\end{array}$ & $\begin{array}{l}\text { Thermal load } \\
\text { (C) }\end{array}$ & $\begin{array}{l}\text { Thermal load } \\
\text { (D) }\end{array}$ & $\begin{array}{c}\text { Thermal load } \\
\text { (E) }\end{array}$ & $\begin{array}{l}\text { Thermal load } \\
\text { (F) }\end{array}$ & $\alpha_{\mathrm{SOFA}}$ & $\begin{array}{c}\text { Running } \\
\mathrm{O}_{2}\end{array}$ & $P_{\text {NOx }}$ & $P_{\mathrm{Tr}}$ \\
\hline 1 & 50.2 & 588.7 & 123.1 & 156.0 & 166.6 & 172.9 & 203.4 & 0.253 & 2.211 & 87.9 & 0.46 \\
\hline 2 & 57.3 & 589.6 & 123.1 & 155.9 & 166.6 & 173.2 & 203.4 & 0.253 & 2.237 & 86.2 & 0.61 \\
\hline 3 & 217.6 & 598.1 & 123.1 & 155.4 & 166.5 & 173.0 & 203.4 & 0.210 & 2.237 & 47.8 & 2.06 \\
\hline 4 & 250.7 & 599.2 & 122.4 & 155.9 & 166.6 & 173.5 & 203.4 & 0.208 & 2.236 & 39.9 & 2.25 \\
\hline 5 & 440.3 & 603.1 & 123.1 & 157.3 & 166.2 & 173.1 & 203.4 & 0.196 & 2.224 & 56.1 & 2.92 \\
\hline 6 & 479.4 & 603.2 & 123.1 & 160.0 & 166.2 & 173.1 & 203.4 & 0.196 & 2.236 & 15.0 & 2.94 \\
\hline 7 & 416.9 & 586 & & & & & & & & & \\
\hline
\end{tabular}

TABLE 8: Recommended setpoints for inputs at $850 \mathrm{MW}$.

\begin{tabular}{|c|c|c|c|c|c|c|c|c|c|c|}
\hline No. & NOx & $\operatorname{Tr}$ & Thermal load (C) & Thermal load (D) & Thermal load (E) & Thermal load (F) & $\alpha_{\mathrm{SOFA}}$ & Running $\mathrm{O}_{2}$ & $P_{\mathrm{NOx}}$ & $P_{\mathrm{Tr}}$ \\
\hline 1 & 138.0 & 592.1 & 151.1 & 164.4 & 206.4 & 251.3 & 0.243 & 2.171 & 67.1 & 0.87 \\
\hline 2 & 148.0 & 593.4 & 152.6 & 164.4 & 205.7 & 251.3 & 0.197 & 2.171 & 64.7 & 1.09 \\
\hline 3 & 181.9 & 599.8 & 151.3 & 164.4 & 186.3 & 251.3 & 0.184 & 2.229 & 56.6 & 2.18 \\
\hline 4 & 224.9 & 602.1 & 153.1 & 164.4 & 186.3 & 251.3 & 0.184 & 2.948 & 46.4 & 2.57 \\
\hline 5 & 362.3 & 606.7 & 151.1 & 164.4 & 186.3 & 251.3 & 0.201 & 4.479 & 13.6 & 3.36 \\
\hline 6 & 365.1 & 607.1 & 151.1 & 164.4 & 186.3 & 251.0 & 0.185 & 4.478 & 13.0 & 3.42 \\
\hline 7 & 419.5 & 587 & & & & & & & & \\
\hline
\end{tabular}

\section{Conclusions}

This paper puts a new point on optimizing NOx emission and reheat steam temperature simultaneously using a joint optimization method, in which a set of rdCV-MONPLS strategies were proposed as predictors in three cases of load such as $650 \mathrm{MW}, 800 \mathrm{MW}$, and $850 \mathrm{MW}$. Compared with another three well-known methods (k-foldMO-NPLS, SVR, and ANN), this method can achieve higher predictive accuracies. Then, MO-ABC was applied to search the optimal set point of controllable process variables to reduce $\mathrm{NOx}$ emission and improve reheat steam temperature. Results showed that our joint optimization of boiler combustion with $\mathrm{MO}-\mathrm{ABC}$ provided a set of tradeoff solutions and outperformed that obtained by NSGA-II and experimental data. This implies that our proposed method on boiler combustion optimization can guarantee higher economy as well as safety control of combustion systems.

\section{Data Availability}

The data used to support the findings of this study are included within the supplementary information file.

\section{Conflicts of Interest}

The authors declare no conflicts of interest. 


\section{Acknowledgments}

This work was supported by the National Natural Science Foundation of China (Grant no. 51676034) and the Fundamental Research Funds for the Central Universities (Grant no. 2242019K40002).

\section{Supplementary Materials}

Appendix A: experimental data are provided when the boiler worked stably, respectively, at $650 \mathrm{MW}, 800 \mathrm{MW}$, and $850 \mathrm{MW}$. More details can be viewed in Tables A1-A3. Table A1: the steady-state experimental data of $650 \mathrm{MW}$. Table A2: the steady-state experimental data of $800 \mathrm{MW}$. Table A3: the steady-state experimental data of $850 \mathrm{MW}$. Appendix B: Table B1: lower and upper bounds of inputs of the rdCVMO-NPLS model at $650 \mathrm{MW}$. Table B2: lower and upper bounds of inputs of the rdCV-MO-NPLS model at $800 \mathrm{MW}$. Table B3: lower and upper bounds of inputs of the rdCVMO-NPLS model at $850 \mathrm{MW}$. (Supplementary Materials)

\section{References}

[1] Z. Wei, X. Li, L. Xu, and C. Tan, "Optimization of operating parameters for low NOx emission in high-temperature air combustion," Energy \& Fuels, vol. 26, no. 5, pp. 2821-2829, 2012.

[2] S. Belosevic, V. Beljanski, I. Tomanovic, N. Crnomarkovic, D. Tucakovic, and T. Zivanovic, "Numerical analysis of NOx control by combustion modifications in pulverized coal utility boiler," Energy \& Fuels, vol. 26, no. 1, pp. 425-442, 2012.

[3] S. Dal Secco, O. Juan, M. Louis-Louisy, J. Y. Lucas, P. Plion, and L. Porcheron, "Using a genetic algorithm and CFD to identify low NOx configurations in an industrial boiler," Fuel, vol. 158, pp. 672-683, 2015.

[4] H. Zhou, K. Cen, and J. Fan, "Modeling and optimization of the nox emission characteristics of a tangentially fired boiler with artificial neural networks," Energy, vol. 29, no. 1, pp. 167-183, 2004.

[5] P. Ilamathi, V. Selladurai, K. Balamurugan, and V. T. Sathyanathan, "ANN-GA approach for predictive modeling and optimization of NOx emission in a tangentially fired boiler," Clean Technologies and Environmental Policy, vol. 15, no. 1, pp. 125-131, 2013.

[6] Z. Wei, X. Li, L. Xu, and Y. Cheng, "Comparative study of computational intelligence approaches for NOx reduction of coal-fired boiler," Energy, vol. 55, no. 18, pp. 683-692, 2013.

[7] P.-H. Wang, L.-L. Li, Q. Chen, and Y.-H. Dong, "Research on applications of artificial intelligence to combustion optimization in a coal-fired boiler," Proceedings of Chinese Society for Electrical Engineering, vol. 24, no. 4, p. 5, 2004.

[8] X. Peng and P. Wang, "An improved multiobjective genetic algorithm in optimization and its application to high efficiency and low NOx emissions combustion," in Proceedings of the 2009 Asia-pacific Power and Energy Engineering Conference, pp. 1-4, IEEE, Wuhan, China, March 2009.

[9] H. Zhou, K. Cen, and J. Fan, "Multi-objective optimization of the coal combustion performance with artificial neural networks and genetic algorithms," International Journal of Energy Research, vol. 29, no. 6, pp. 499-510, 2005.

[10] Y. Zhang, Y. Ding, Z. Wu, L. Kong, and T. Chou, "Modeling and coordinative optimization of NOx emission and efficiency of utility boilers with neural network," Korean Journal of Chemical Engineering, vol. 24, no. 6, pp. 11181123, 2007.

[11] Y. Zheng, X. Gao, and C. Sheng, "Impact of co-firing lean coal on NOx emission of a large-scale pulverized coal-fired utility boiler during partial load operation," Korean Journal of Chemical Engineering, vol. 34, no. 4, pp. 1273-1280, 2017.

[12] F. M. Ham and I. Kostanic, "Partial least-squares: theoretical issues and engineering applications in signal processing," Mathematical Problems in Engineering, vol. 2, no. 1, pp. 63-93, 1996.

[13] Z. Meng, S. Zhang, Y. Yang, and M. Liu, "Nonlinear partial least squares for consistency analysis of meteorological data," Mathematical Problems in Engineering, vol. 2015, Article ID 143965, 8 pages, 2015.

[14] X. Dong and J. Wang, "Modeling and optimization for piercing efficiency and energy consumption based on mean value substaged KELM-PLS and GA method," Mathematical Problems in Engineering, vol. 2014, Article ID 132654, 12 pages, 2014.

[15] P. Filzmoser, B. Liebmann, and K. Varmuza, "Repeated double cross validation," Journal of Chemometrics, vol. 23, no. 4, pp. 160-171, 2009.

[16] S. Wold, N. Kettaneh-Wold, and B. Skagerberg, "Nonlinear PLS modeling," Chemometrics and Intelligent Laboratory Systems, vol. 7, no. 1-2, pp. 53-65, 1989.

[17] R. Rosipal, "Nonlinear Partial Least Squares: An Overview," in Chemoinformatics and Advanced Machine Learning Perspectives: Complex Computational Methods and Collaborative Techniques, pp. 169-189, IGI Global, Hershey, PA, USA, 2011.

[18] G. Baffi, E. B. Martin, and A. J. Morris, "Non-linear projection to latent structures revisited: the quadratic PLS algorithm," Computers \& Chemical Engineering, vol. 23, no. 3, pp. 395411, 1999.

[19] D. Karaboga, An Idea Based on Honey Bee Swarm for Numerical Optimization (Technical Report-tr06), Technical Report, Erciyes University, Engineering Faculty, Computer Engineering Department, Kayseri, Turkey, 2005.

[20] H. Wang, H. Liang, and L. Gao, "Using an improved artificial bee colony algorithm for parameter estimation of a dynamic grain flow model," Mathematical Problems in Engineering, vol. 2018, Article ID 2132963, 11 pages, 2018.

[21] F. Wahid and D. H. Kim, "An efficient approach for energy consumption optimization and management in residential building using artificial bee colony and fuzzy logic," Mathematical Problems in Engineering, vol. 2016, Article ID 9104735, 13 pages, 2016.

[22] G. Deng, H. Yang, and S. Zhang, "An enhanced discrete artificial bee colony algorithm to minimize the total flow time in permutation flow shop scheduling with limited buffers," Mathematical Problems in Engineering, vol. 2016, Article ID 7373617, 11 pages, 2016.

[23] L. Sun, J. Hu, and H. Chen, "Artificial bee colony algorithm based on K-means clustering for multiobjective optimal power flow problem," Mathematical Problems in Engineering, vol. 2015, Article ID 762853, 18 pages, 2015.

[24] D. Karaboga and B. Akay, "A comparative study of artificial bee colony algorithm," Applied Mathematics and Computation, vol. 214, no. 1, pp. 108-132, 2009.

[25] R. Akbari, R. Hedayatzadeh, K. Ziarati, and B. Hassanizadeh, "A multi-objective artificial bee colony algorithm," Swarm and Evolutionary Computation, vol. 2, no. 1, pp. 39-52, 2012.

[26] D. Karaboga and B. Basturk, "A powerful and efficient algorithm for numerical function optimization: artificial bee 
colony (ABC) algorithm," Journal of Global Optimization, vol. 39, no. 3, pp. 459-471, 2007.

[27] M. Mernik, S.-H. Liu, D. Karaboga, and M. Črepinšek, "On clarifying misconceptions when comparing variants of the artificial bee colony algorithm by offering a new implementation," Information Sciences, vol. 291, pp. 115-127, 2015.

[28] M. Li and X. Yao, "Quality evaluation of solution sets in multiobjective optimisation: a survey," ACM Computing Surveys (CSUR), vol. 52, no. 2, pp. 1-38, 2019. 


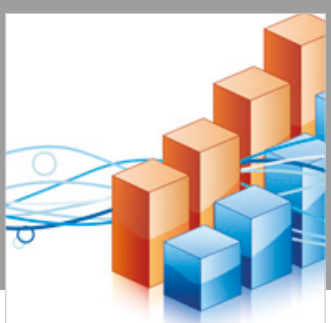

Advances in

Operations Research

\section{-n-m}
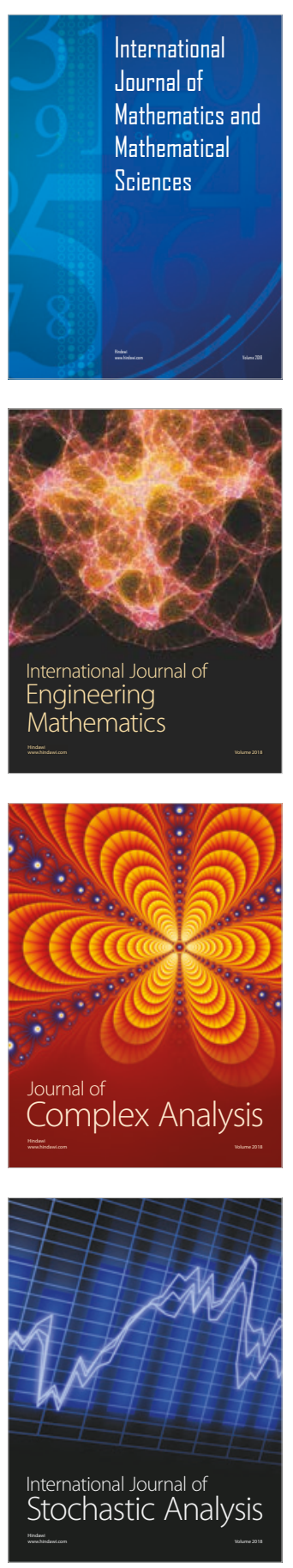
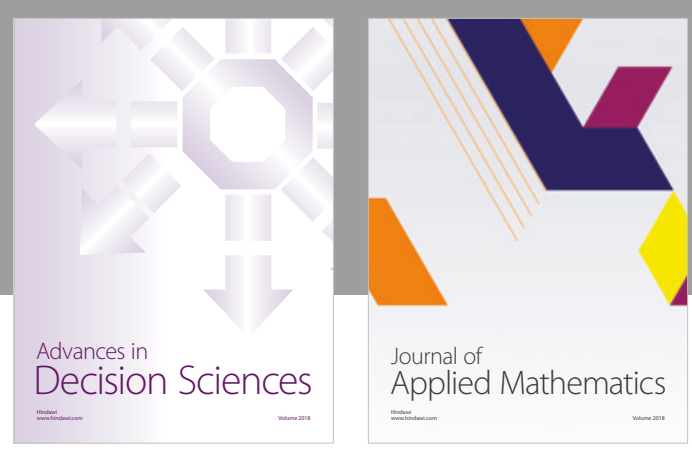

Journal of

Applied Mathematics
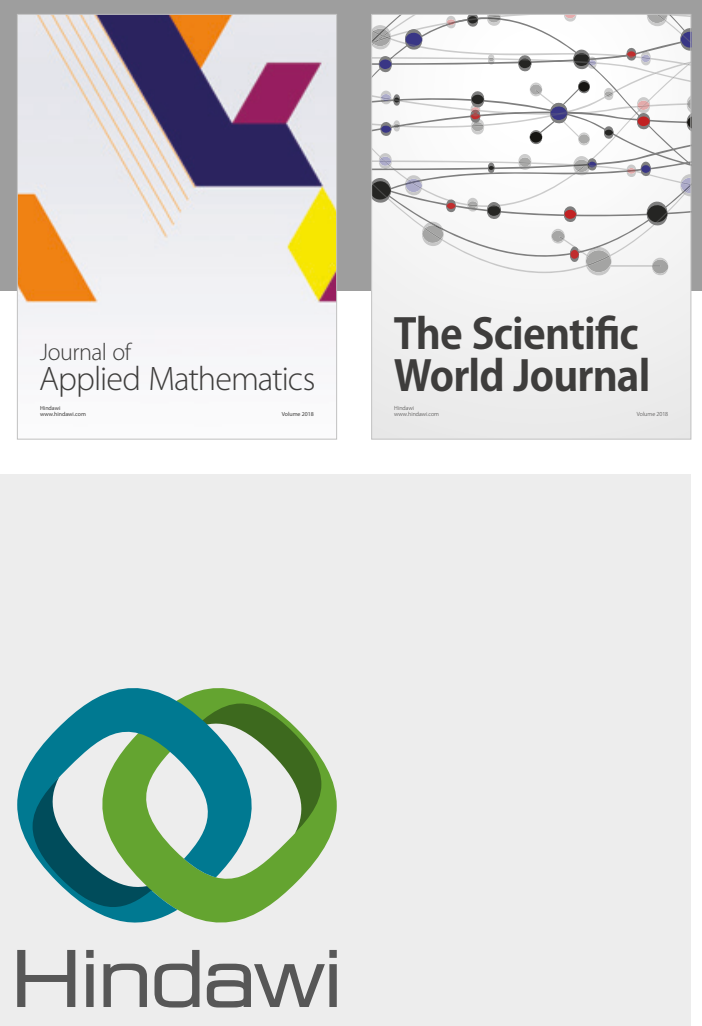

Submit your manuscripts at

www.hindawi.com

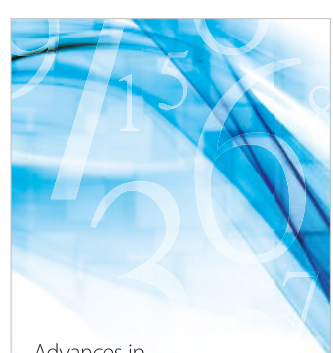

Advances in
Numerical Analysis
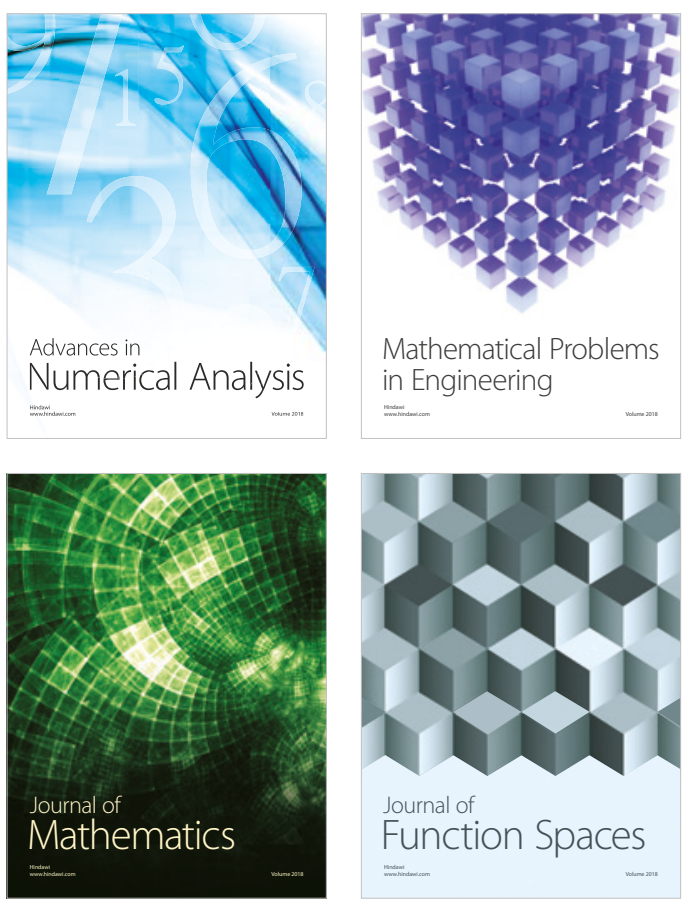

Mathematical Problems in Engineering

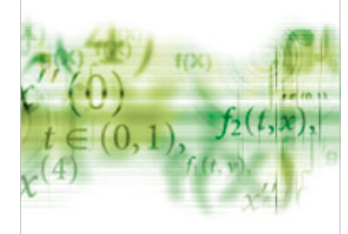

International Journal of

Differential Equations

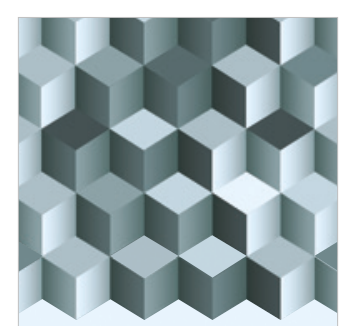

Journal of

Function Spaces

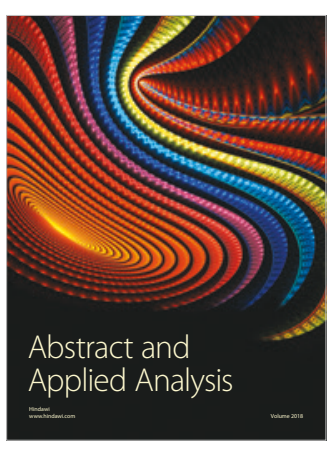

The Scientific

World Journal

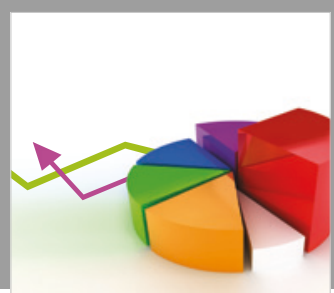

Journal of

Probability and Statistics
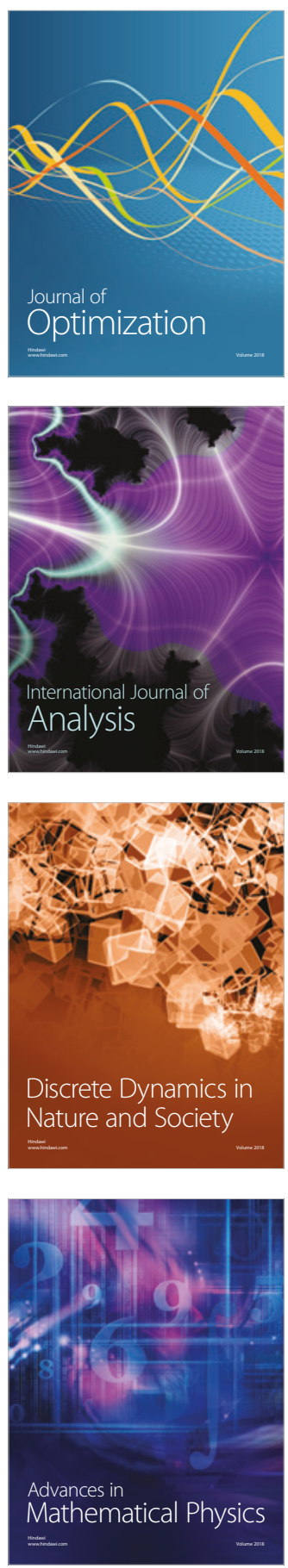